\section{P259 INTERPROFESSIONAL TEACHING ON EATING DISORDERS IN CHILDREN: A QUALITATIVE FEEDBACK STUDY}

${ }^{1} \mathrm{SC}$ Richardson*, ${ }^{2} \mathrm{OM}$ Neylon, ${ }^{1,3}{ }^{\mathrm{E}}$ Barrett. ${ }^{1}$ Children's University Hospital, Temple St, Dublin, Ireland; ${ }^{2}$ University Hospital Limerick, Limerick, Ireland; ${ }^{3}$ University College Dublin, Dublin, Ireland

\subsection{6/archdischild-2019-epa.609}

Background We report on an interdisciplinary training day regarding the acute assessment and management of eating disorders in paediatric settings. The Centre for Advancement of Interprofessional education defines Interprofessional education (IPE) as 'occasions when two or more professions learn with, from and about each other to improve collaboration and the quality of care'.

Aim Our aim was to assess the response to IPE teaching session on Eating disorders, a condition requiring management by a wide multidisciplinary team.

Methods An electronic survey on Survey Monkey was distributed to all registered attendees following a teaching seminar on Eating Disorders in University Hospital Limerick in November 2018. As this was an educational survey of adult learners it was deemed ethics approval was not required.

Results $41.5 \%$ (47/113) people completed the online survey. There were seven different professional groups represented. The largest group were acute setting paediatric nurses $23.4 \%$ (11/47). The majority of respondents $(58.97 \%$ 23/47) work in acute paediatric services while another 30\% (12/47) work in CAMHS. Over 95\% (45/47) felt their learning needs were met. On a Likert scale all professional groups gave positive responses regarding their understanding of other professionals' roles in management of Eating disorders. While 44.7\% (21/ 47) felt it changed their understanding of other professionals' role a little, a further $40.45 \%(19 / 47)$ felt it changed their understanding a lot. $86 \%(37 / 43)$ were extremely satisfied with the study day.

Conclusion The study day was well received and had a positive impact on most attendees regarding interprofessional working. In addition, other learning needs regarding eating disorders were met. Good interprofessional communication and management is the cornerstone of patient care. It is important to provide multidisciplinary education sessions which highlight the unique role each professional group brings to the management of the patient and helps to improve the understanding of the interface between different professional groups in the management of a condition.

\section{P260 PARENTAL SATISFACTION WITH JUNIOR DOCTOR CONSULTATIONS}

1,2Paddy McCrossan*, ${ }^{2}$ Deirdre Kelly, ${ }^{2}$ Joy Tan, ${ }^{2}$ Kate Rose, ${ }^{1}$ Naomi McCallion. ${ }^{1}$ Royal College of Surgeons in Ireland, Dublin, Ireland; ' ${ }^{2}$ Children's University Hospital, Temple Street, Dublin, Ireland

\subsection{6/archdischild-2019-epa.610}

Aims To determine parental satisfaction of a consultation with a junior doctor in a paediatric hospital, with reference to the affective aspects of the medical council's domains of good professional practice.

Methods Administering a five-point Likert scale questionnaire $(1=$ strongly disagree, $5=$ strongly agree $)$ to a sample of parents of paediatric patients' following a once-off consultation with a junior doctor.

The questionnaire comprised five questions which examined the doctors perceived; empathy, professionalism communication, confidence and the parent's overall satisfaction with the consultation.

We sought to determine whether the gender, age or prior hospital experience has an effect on parents perceived satisfaction.

Results 102 questionnaires were completed.

Abstract 260 Table 1 Likert response to each item on the parental satisfaction questionnaire

\begin{tabular}{llllll}
\hline Likert scale & $\mathbf{1}$ & $\mathbf{2}$ & $\mathbf{3}$ & $\mathbf{4}$ & $\mathbf{5}$ \\
\hline 1. Empathy $(\mathrm{n}=)$ & 3 & 1 & 3 & 19 & 75 \\
2. Professionalism $(\mathrm{n}=)$ & 3 & 0 & 1 & 18 & 79 \\
3. Communication $(\mathrm{n}=)$ & 3 & 0 & 2 & 18 & 78 \\
4. Confidence $(\mathrm{n}=)$ & 4 & 0 & 2 & 13 & 82 \\
5. Satisfaction $(\mathrm{n}=)$ & 4 & 0 & 1 & 16 & 80 \\
\hline
\end{tabular}

A Cronbach's alpha of 0.986 was achieved for the whole questionnaire which demonstrates a near-perfect internal consistency and thus reliable test results.

Almost $80 \%$ of responses were rated 'highly agree' with regards to all five questions and approximately $95 \%$ of all responses were rated at least 'agree'.

There was no statistically significant difference in responses dependent on the gender of the parent or whether they had prior experience of attending the hospital with their child (Mann Whitney U, p >0.05 for all of the questions).

There was no statistically significant difference in responses dependent on the age of the parent (Kruss Kall Wallis, $\mathrm{p}>0.05$ for all of the questions).

Conclusion Parents are overwhelmingly positive in their overall satisfaction with the paediatric consultation and also each 'affective' aspect of it.

There was no significant difference in responses depending on age, gender or previous experience of the hospital.

These results are reassuring with regards to trainee performance within the affective aspects of the Medical Council's domains of good professional practice.

\section{P261 ARE NON-SCHEME PAEDIATRIC JUNIOR DOCTORS GETTING ACCESS TO CONTINUOUS PROFESSIONAL DEVELOPMENT (CPD) IN IRELAND?}

Engy Shehata, Sean Armstrong* , Adrienne Foran. Rotunda Hospital, Dublin, Ireland

\subsection{6/archdischild-2019-epa.611}

Aim To determine if paediatric doctors who are not basic (BST) or higher (HST) specialist trainees, get adequate opportunities to maintain their CPD.

Methods A survey of 18 questions (survey monkey) was created that included 17 closed and one open question. Surveys were circulated to paediatric NCHDs by: Email through HR departments, and by lead author via Whatsapp and Facebook. Responses were collected between 27th May and 3rd July 2018. 